\title{
Surface Texturing of CVD Diamond Assisted by Ultrashort Laser Pulses
}

\author{
Daniele M. Trucchi ${ }^{1, *}$ (i) , Alessandro Bellucci ${ }^{1}$, Marco Girolami ${ }^{1}$ (D), Matteo Mastellone ${ }^{1}$ and \\ Stefano Orlando ${ }^{2}$ \\ 1 DiaTHEMA Lab, Istituto di Struttura della Materia (ISM-CNR), Montelibretti Section, \\ 00015 Monterotondo Scalo (RM), Italy; alessandro.bellucci@ism.cnr.it (A.B.); \\ marco.girolami@ism.cnr.it (M.G.); matteo.mastellone@ism.cnr.it (M.M.) \\ 2 Istituto di Struttura della Materia (ISM-CNR), Tito Scalo Section, Zona Industriale, 85050 Tito Scalo (PZ), \\ Italy; stefano.orlando@ism.cnr.it \\ * Correspondence: daniele.trucchi@ism.cnr.it; Tel.: +39-06-90672-558
}

Academic Editor: Ivan Buijnsters

Received: 1 August 2017; Accepted: 28 October 2017; Published: 3 November 2017

\begin{abstract}
Diamond is a wide bandgap semiconductor with excellent physical properties which allow it to operate under extreme conditions. However, the technological use of diamond was mostly conceived for the fabrication of ultraviolet, ionizing radiation and nuclear detectors, of electron emitters, and of power electronic devices. The use of nanosecond pulse excimer lasers enabled the microstructuring of diamond surfaces, and refined techniques such as controlled ablation through graphitization and etching by two-photon surface excitation are being exploited for the nanostructuring of diamond. On the other hand, ultrashort pulse lasers paved the way for a more accurate diamond microstructuring, due to reduced thermal effects, as well as an effective surface nanostructuring, based on the formation of periodic structures at the nanoscale. It resulted in drastic modifications of the optical and electronic properties of diamond, of which "black diamond" films are an example for future high-temperature solar cells as well as for advanced optoelectronic platforms. Although experiments on diamond nanostructuring started almost 20 years ago, real applications are only today under implementation.
\end{abstract}

Keywords: diamond; laser; ultrashort pulse; surface texturing; black diamond; solar radiation capturing; solar energy conversion

\section{Introduction}

Diamond is a semiconductor with a wide bandgap of $5.47 \mathrm{eV}$. Thin films are the standardized form of diamond feasible for advanced industrial applications and are developed by chemical vapor deposition (CVD). The extreme robustness of diamond has also driven the development of ultraviolet (UV) detectors (wavelength $<225 \mathrm{~nm}$, corresponding to photon energies larger than the diamond bandgap) [1,2], ionizing radiation [3], and nuclear detectors [4]. Intrinsic diamond is characterized by the peculiarity of being electrically insulating and thermally conductive, with the highest thermal conductivity among the solids ( $22 \mathrm{~W} / \mathrm{cm} \cdot \mathrm{K})$ [5]. Diamond can be doped in a standard way by dopant atoms, introduced in the lattice during the deposition or by ion implantation. Boron atoms are used for p-type doping (donor level of $0.39 \mathrm{eV}$ ) and nitrogen atoms for n-type doping. However, with a donor level at $1.7 \mathrm{eV}$ from the conduction band minimum, substitutional nitrogen to carbon atoms do not induce an efficient activation of carriers at room temperature. Conversely, the introduction of phosphorous atoms during the growth of diamond is becoming an appealing tool for the development of n-type doping with an activation energy of about $0.6 \mathrm{eV}$ [6-8]. A technological alternative is surface-transfer doping by hydrogen termination [9]. It induces a p-type conductivity caused by the 
formation of a 2D hole gas [10] that was exploited for the development of planar devices for high frequency [11,12] and high power electronics [13].

Initially, the use of lasers was considered a technologically attractive tool for shaping the morphology and structure of materials into microelectromechanical systems (MEMSs) for applications such as gyroscopes, accelerometers, etc. Apart from the laser cutting and surface polishing, performed since the late $60 \mathrm{~s}$ for jewelry, the laser treatment of diamond, disclosing interesting applications connected to this material with outstanding physical properties, was applied relatively late for the high ablation threshold and high transparency of diamond to the wavelength of standard power lasers. However, laser-induced structuring of diamond was considered an appealing solution owing to the extreme hardness and high thermal conductivity hampering mechanical treatments, and to the chemical inertness hampering chemical-based diamond selective etching processes. The development of high power pulsed excimer lasers, with a wavelength shorter or comparable to the diamond absorption edge of $235 \mathrm{~nm}$ [14], led to the consequential possibility of maximizing the interaction between diamond and the shaping radiation, thus allowing an effective microstructuring. Laser-assisted modifications of diamond structure were found to alter significantly the optical properties of diamond, paving the way for the development of infrared (IR) optical filters when periodic structures were fabricated on the surface or in the bulk [15].

When ultrashort pulse (i.e., picosecond or femtosecond range) lasers became widespread, the first advantage was recognized to be the extremely reduced thermal effects of the treatments compared to the use of longer laser pulses (i.e., longer than nanosecond range). As shown in Figure 1a, a significant difference consists of a more accurate processing of the material structure, with the absence of melted regions or of reduced structural microcracks close to the treated volume [16]. On the other hand, ultrashort laser pulses transport a very high radiation power, able to trigger non-linear effects such as multiphotonic absorption (Figure 1b), resulting in the capability to strongly interact with dielectrics and wide bandgap semiconductors such as diamond, even on their surface. Indeed, the interaction of ultrashort laser pulses with matter was found to produce structures called laser-induced periodic surface structures (LIPSSs), also with subwavelength periodicity, thus allowing a transition from the micro- to nanostructuring of the surface. This paved the route for the fabrication of optical devices operating in the visible wavelength spectrum, including diamond as a candidate material. An even more recent finding connected to the fabrication of laser subwavelength LIPSSs consists of the capability of engineering the diamond electronic bandgap, which is fundamental for developing diamond-based optoelectronic devices active in the visible band.

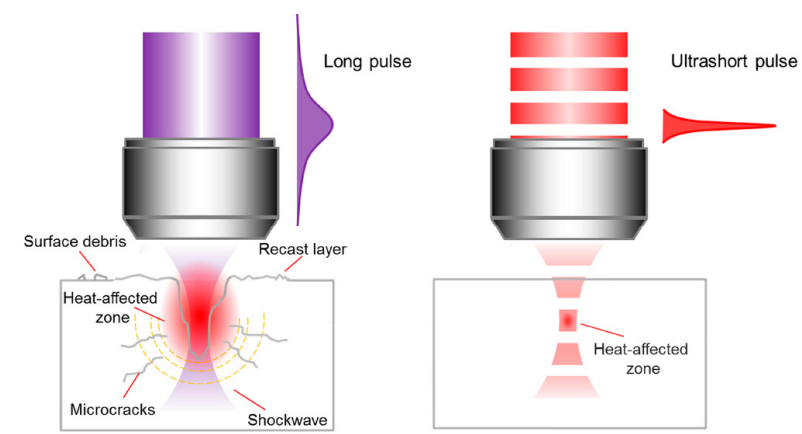

(a)
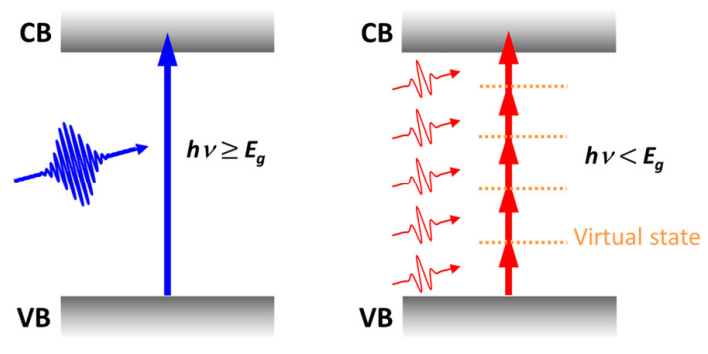

(b)

Figure 1. (a) Difference in the treatment effects in the case of long and ultrashort pulses for a transparent material to the laser wavelength; (b) effect of the single photon absorption occurring only with an energy larger than the semiconductor/dielectric bandgap compared to the multiphoton absorption of sub-bandgap photons [17] (CC BY 4.0). 
This review is structured to start from a first general part, based on the modification of materials performed by ultrashort laser pulses, to successively pass through the discussion of laser-assisted experiments on diamond surface. Then, the topic is progressively specialized into the description of black diamond films' optical and electronic properties. Finally, the applications for nanotextured diamond films conclude the manuscript.

\section{Surface Modification of Materials by Ultrashort Laser Pulses}

Laser pulses impinging on a solid are able to transfer a high energy in a very short time, resulting in a huge amount of transferred power. With pulses longer than the nanosecond range, including continuous wave lasers, a laser beam with a wavelength $\lambda$ has to interact with a material accounting for a considerable value of absorption coefficient at $\lambda$. If the power density is larger than the material threshold, the absorption of the laser radiation allows the structural modification of such material. For example, non-defected semiconductors have a sudden threshold in the absorption coefficient enabling interaction with light characterized by a photon energy higher than the bandgap (or wavelength shorter than that corresponding to the bandgap energy).

Pulses with durations in the femtosecond range are able to induce non-linear effects during the photon-matter interaction, such as multiphoton absorption. As previously discussed, femtosecond length pulses demonstrated the capability to limit the structural modifications only in the laser focal volume and to minimize thermal effects towards the zones not involved by the interaction. The absorption of ultrashort pulses can cause an optical breakdown in the material followed by avalanche ionization, which depends linearly on the radiation intensity and slightly on the bandgap of the dielectric. These effects modify the matter almost independently from the specific material [18]. Another advantage coming from the interaction between a crystal and ultrashort pulses was found in the possibility of fabricating periodic structures at the nanoscale on the crystal surface. This allowed the nanostructuring of a wide range of materials which were also nominally transparent to the specific laser wavelength. Even though the formation of LIPSSs was previously observed during treatments performed with other lasers and was found to have a period comparable to the laser wavelength, subwavelength LIPSSs, ranging from tens to hundreds of nanometers, were only formed with ultrashort lasers. Specifically, two different LIPSSs were obtained: one type characterized by a subwavelength periodicity $\Lambda_{\mathrm{HSF}}$ (i.e., high spatial frequency, HSF) and the second one with a periodicity $\Lambda_{\text {LSF }}$ (i.e., low spatial frequency, LSF) approaching or even larger than the laser wavelength. The origin of the two different LIPSSs is a debated mechanism that was modeled in several works (e.g., $[19,20])$ and that will be specifically reported for diamond in the following pages.

Transparent materials such as glass [17], silica [21], and $\mathrm{ZnO}$ [22] were successfully nano/ micromachined with the use of ultrashort laser pulses [23], whereas the development of advanced materials such as black silicon [24] and the related photodetectors, characterized by an extended responsivity towards the IR band [25], represented a clear example of the potential of femtosecond laser-assisted modifications in enhancing the optical and electronic properties of semiconductors. A few other examples, picked from an extended literature, of surface-treated materials with tailored optical properties are texturing-induced colored noble metals [26,27], copper [28], refractory metals [29,30], steel [31], engineered ceramics materials for selective solar absorbers [32,33], different structures of $\mathrm{SiC}[34,35]$ and other III-V semiconductors used in electronics, such as GaAs, GaP, and InP [36].

\section{Texturing of Diamond Surface}

Laser treatment is progressively acquiring attention from the scientific and industrial communities as an extremely appealing tool for introducing defects into the diamond bulk and surface. Bulk diamond-to-graphite laser-induced transformations with micrometer resolution are interesting for the local tailoring of the electric and optical properties of two materials so similar but so different as graphite and diamond [37], with the aim of developing low electric conductivity paths [38] for 3D detectors [39-41], photonic crystals for the THz region [42], and electron emission devices [43]. 
Ultrashort laser pulse treatments in the bulk proved also to be effective in inducing the formation of $\mathrm{NV}^{-}$centers $[44,45]$, which act as optically active sources for future quantum information technologies.

However, the aim of this paper is limited to the discussion of the modifications induced by the laser on the diamond surface. Surface texturing of diamond was performed initially by using a nanosecond-pulse excimer laser (ArF with $\lambda=193 \mathrm{~nm}$ or $\mathrm{KrF}$ with $\lambda=248 \mathrm{~nm}$, corresponding to a photon energy over or close to the diamond bandgap) for the fabrication of periodic optical gratings with micrometer resolution. Both one-dimensional and two-dimensional [46-49] extremely well-defined periodic structures demonstrated a significant antireflective selectivity in the IR wavelength range, where the micrometer periodic grating is comparable or smaller than the radiation wavelength to operate on. Figure 2 shows the fabrication of (a) linear grating; (b) of a photonic crystal; and (c) of pyramidal periodic structures on the surface of CVD diamond films. In addition, a XeCl excimer laser with a longer wavelength $(\lambda=308 \mathrm{~nm})$ was used to produce sub-micrometric $2 \mathrm{D}$ periodic structures on the diamond surface [50].
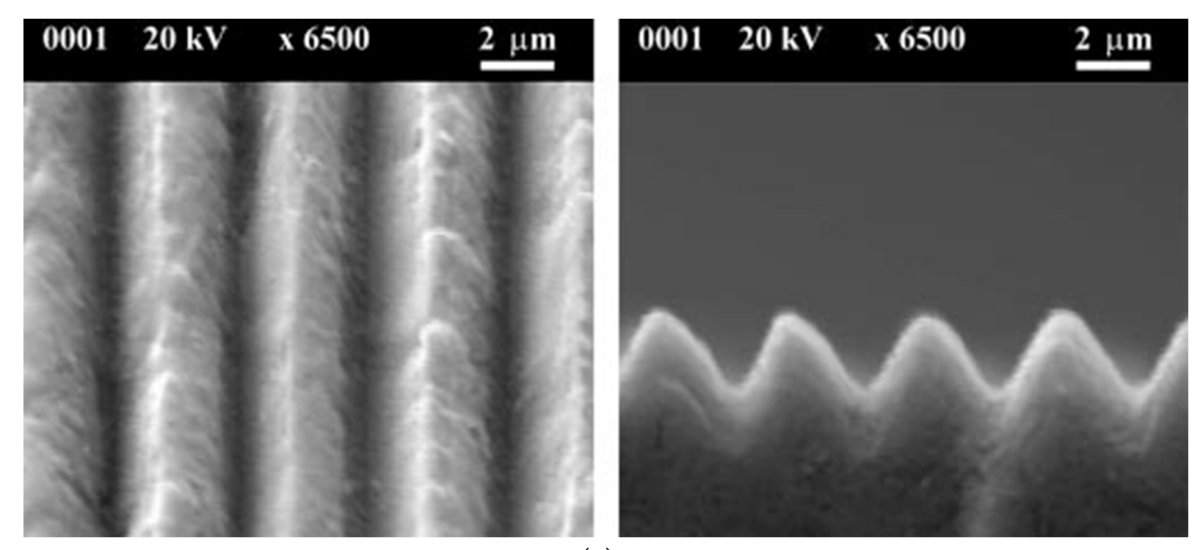

(a)

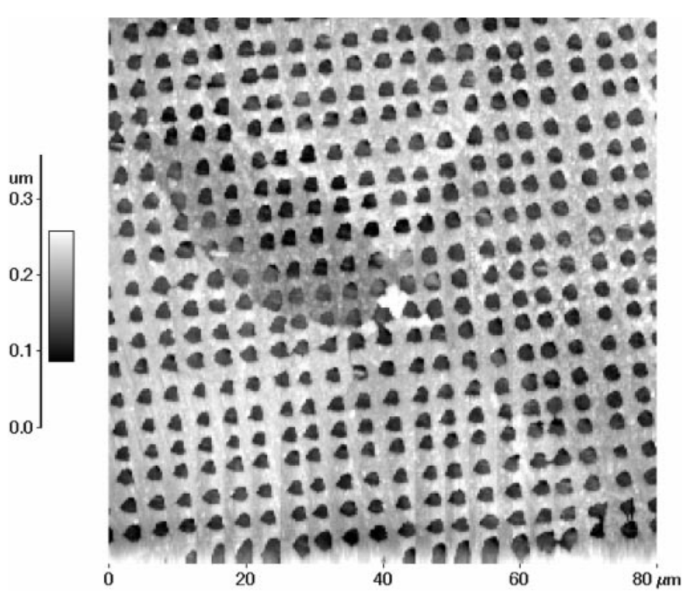

(b)

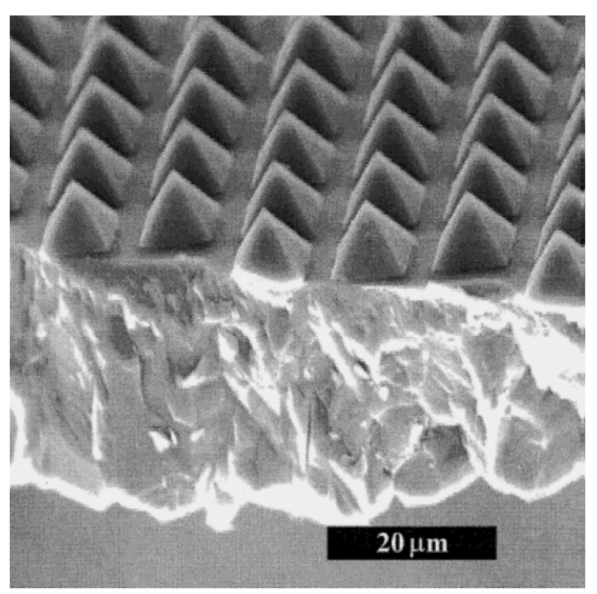

(c)

Figure 2. Scanning electron micrographs of periodic structures developed by UV excimer laser. (a) One-dimensional grating [47] (Copyright 1999 Springer); (b) Two-dimensional photonic crystal [48] (Copyright 2000 Springer); (c) Two-dimensional pyramidal grating [46] (Copyright 1991 John Wiley \& Sons, Inc.).

It is interesting to mention that the transition from micro- to nanostructuring already started with the ultra-precise use of nanosecond excimer lasers by

- $\quad$ Finely operating in the proximity of the diamond ablation threshold [51], studied as a function of the pulse length $\tau$. Figure 3 shows a constant ablation threshold in the ultrashort regime (due to the mostly surface interaction between laser and diamond) of about $3 \mathrm{~J} / \mathrm{cm}^{2}$ (higher than the 
value $1.6 \mathrm{~J} / \mathrm{cm}^{2}$ found in [52]), increasing with a $\tau^{1 / 4}$ dependence for pulse duration longer than $10-100 \mathrm{ps}$. The mechanism exploited is a controlled diamond-to-graphite transformation to obtain an extremely accurate nanoablation.

- Applying the two-photon surface excitation for selectively etching the diamond surface $[53,54]$, not needing a transformation of diamond into graphite. The process induces the direct ejection of carbon atoms and is therefore characterized by a lack of fluence threshold, differently from mechanisms of atomic ablation and desorption. Obviously, the technique is extremely sensitive to the linear polarization direction with respect to the crystal-orientation, resulting in different morphologies as shown in Figure 4.

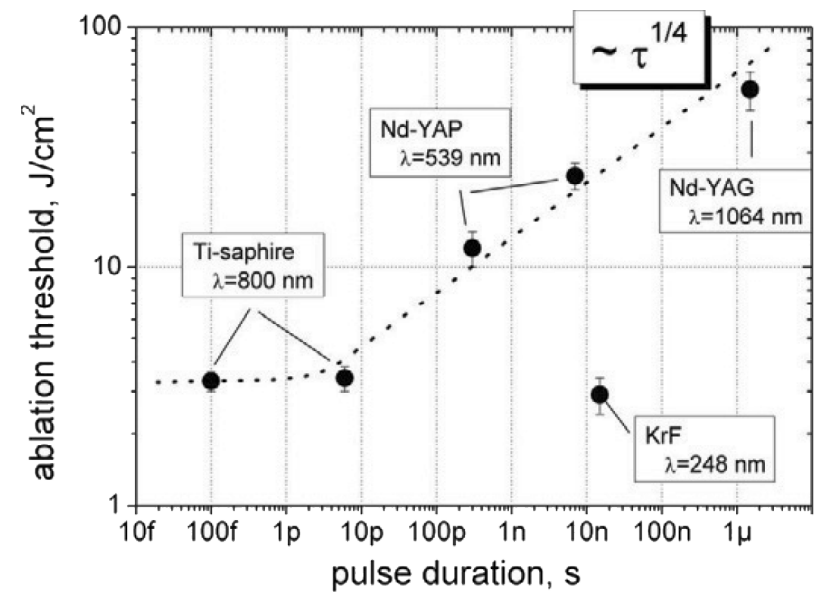

Figure 3. Dependence of the chemical vapor deposition (CVD) diamond ablation threshold on the laser pulse duration [51]. (Copyright 2011 Elsevier).

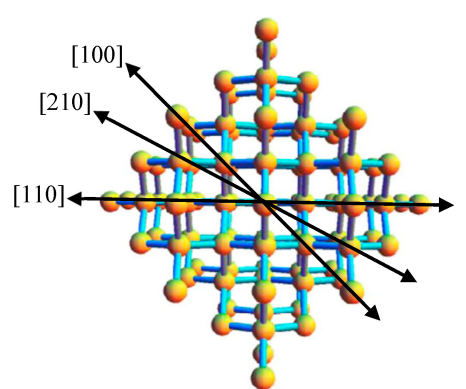

(a)

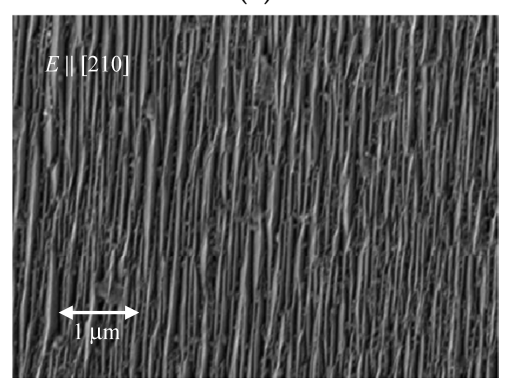

(c)

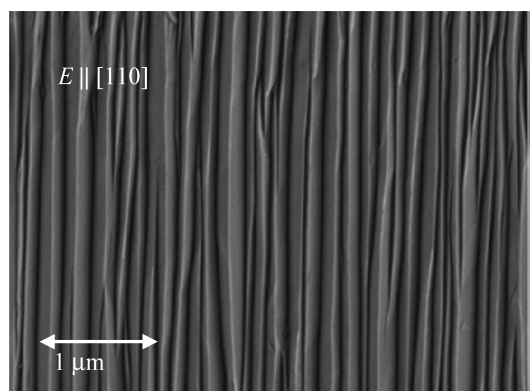

(b)

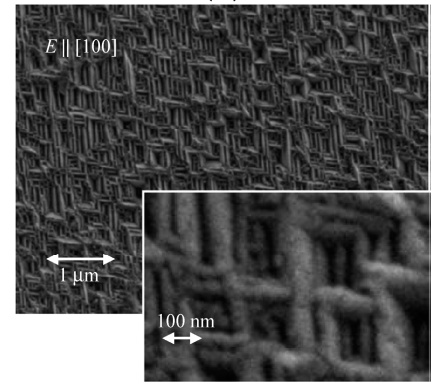

(d)

Figure 4. Patterning of the $\{001\}$ diamond surface with two-photon etching technique. (a) Lattice directions as viewed in the direction of the incident laser beam; (b-d) Scanning electron micrographs for a laser beam at normal incidence with polarizations parallel to [110], [210] and [100]. In each case the laser dose was $10.3 \mathrm{MJ} / \mathrm{cm}^{2}$, and the average depth of material removed was $550 \mathrm{~nm}$ [54]. (Copyright 2014 Macmillan Publishers Ltd.). 
It is worth mentioning that, recently, nanoscale ripples were found and studied in the fabrication of grooves on diamond surfaces [55] performed by a nanosecond-pulsed Nd:YAG laser operating at the second harmonic: $\lambda=532 \mathrm{~nm}$.

On the other hand, diamond nanostructuring by the interaction of linearly polarized ultrashort laser pulses with a diamond surface started in 1999 with the work of Ozkan et al. [56], reporting the formation of LIPSSs (Figure 5a) perpendicular to the polarization direction. LIPSSs had a subwavelength period of 125 and $400 \mathrm{~nm}$ for laser wavelengths of 248 and $825 \mathrm{~nm}$, respectively, and the value of the periodicity was found to depend on the incidence angle. The subwavelength nature of $\Lambda_{\mathrm{HSF}}$ was in contrast with the findings previously obtained on diamond with other lasers, where values approximately equal to the laser wavelength are reported (e.g., $10 \mu \mathrm{m}$ with a $\mathrm{CO}_{2}$ laser [57]).

LSF ripples with the use of fs-lasers were reported in Reference [52] with a laser wavelength of $800 \mathrm{~nm}$, where a periodicity of $0.61 \mu \mathrm{m}$ was found and a modification threshold of $0.4 \mathrm{~J} / \mathrm{cm}^{2}$. On the other hand, Reference [58] highlighted the presence at the same time of three types of LIPSSs on the diamond surface after a fs-laser treatment with wavelengths of 400 and $800 \mathrm{~nm}$ : long LIPSS perpendicular to the laser polarization with periodicity dependent on the incidence angle, short perpendicular LIPSS with periodicity shorter than a third of $\lambda$ and slightly dependent on the incidence angle, and short LIPSS parallel to the laser polarization with constant periodicity independent from the incidence angle.

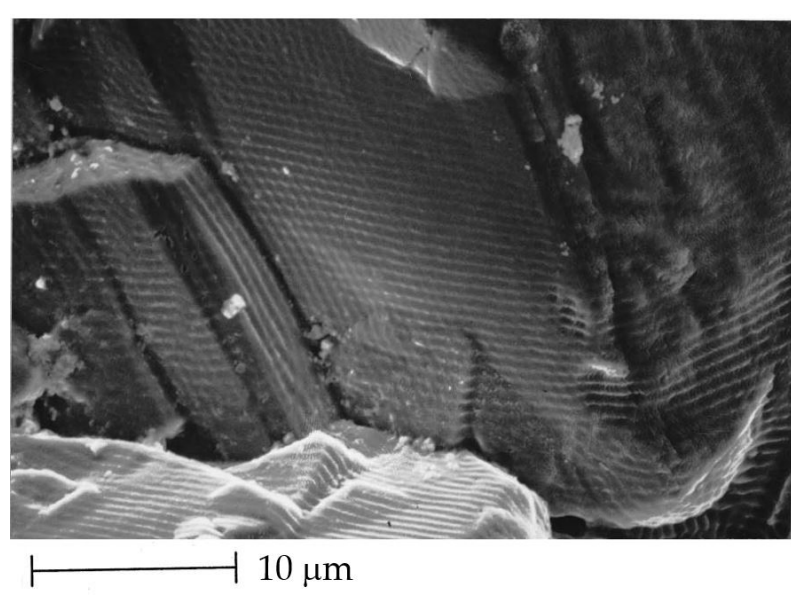

(a)

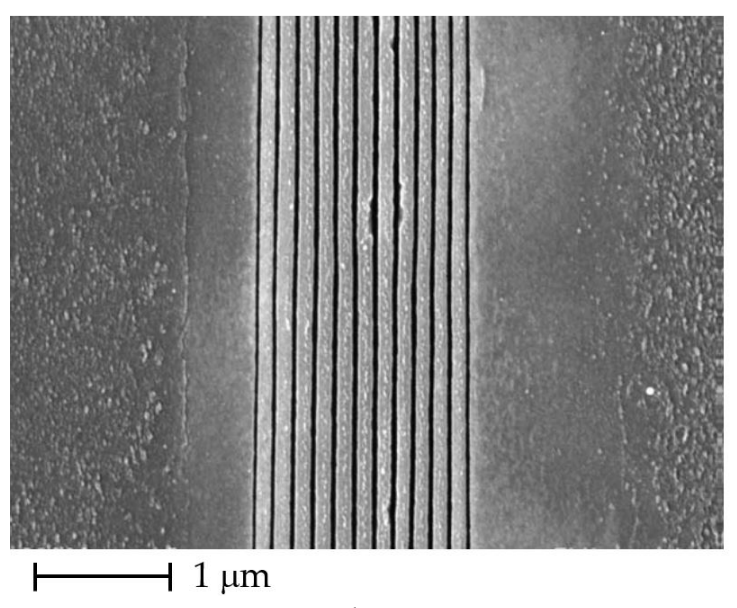

(b)

Figure 5. Scanning electron micrographs of: (a) unpolished CVD diamond irradiated with a Ti-sapphire fs laser (fluence of $2.5 \mathrm{~J} / \mathrm{cm}^{2}, 1000$ pulses, pulse length $150 \mathrm{fs}, \lambda=825 \mathrm{~nm}$ ) with a single interference pattern on the lower grain and two interference patterns crossing each other at 90 degrees on the upper grain [56](Copyright 1999 AIP Publishing); (b) The diamond surface after irradiation with a 1000 pulse train of 120-fs laser pulses at a rate of $250 \mathrm{kHz}$ with a pulse energy of $72 \mathrm{~nJ}$, where the polarization and the scanning directions are indicated by the dotted and solid arrows, respectively [59]. (Copyright 2009 AIP Publishing).

The first attempts to extend the treatment from simple spots to larger surfaces were described in [59], where lines composed by HSF ripples long tenths of millimeters (Figure 5b) and with a period of about $150 \mathrm{~nm}$ were developed at $\lambda=800 \mathrm{~nm}$, after a careful study on the influence of pulse energy on resulting morphology (ranging from 50 to $250 \mathrm{~nJ} /$ pulse with a laser spot size of $2 \mu \mathrm{m}$ diameter).

The understanding of the evolution of texturing parameters as a function of laser wavelength for HSF LIPSSs (both in graphite and diamond) [60] and as a function of number of laser pulses $N$ for LSF LIPSSs [61] was significantly improved with the model proposed therein, which aimed at demonstrating the interference on the diamond surface between the surface plasmon and the 
laser beam as the dominant mechanism. From these works, it is possible to extract very important information for the treatments of the diamond surface: for all the different spatial frequency structures, the periodicity is a decreasing function of the number of pulses impinging on the sample, whereas at a high number of pulses, the periodicity reaches an almost constant period value (Figure 6a). Reference [60] gives the other useful suggestion that the value of the LIPSS periodicity slightly depends also on the fluence, since a small variation from 170 to $190 \mathrm{~nm}$ was found by increasing the fluence from 1.9 to $2.8 \mathrm{~J} / \mathrm{cm}^{2}$.

Reference [62] found that the formation of HSF ripples is favored by a high number of shots and low fluence, whereas LSF structures are dominant when the number of shots is low and the fluence is high. The threshold fluence between the two formation types was found to be $5.4 \mathrm{~J} / \mathrm{cm}^{2}$. The mechanism was recently confirmed also by applying numerical simulations to ablation experiments, finding that HSF ripples form in a narrow range of radiation intensities above the optical breakdown threshold and the transient increase of the carrier density above this threshold causes the formation of near-wavelength LSF surface ripples [63]. The same reference confirmed the dependence of HSF and LSF LIPSSs as a function of the number of pulses (Figure $6 \mathrm{~b}$ ).

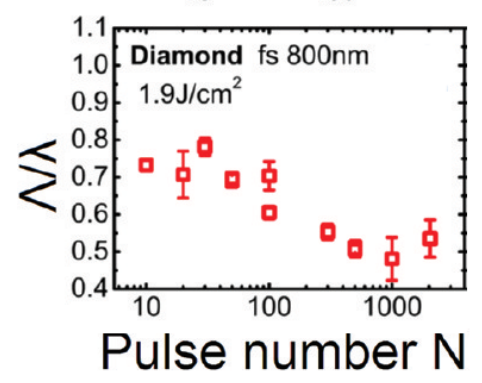

(a)

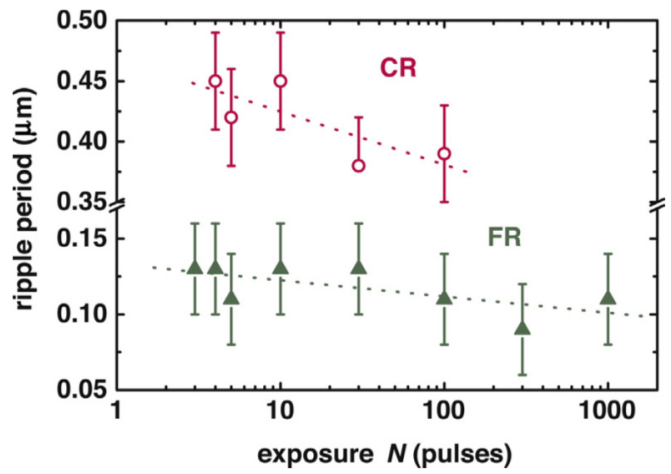

(b)

Figure 6. (a) Dependence of low spatial frequency (LSF) ripples period normalized to $\lambda$ as a function of the pulse number $N$ [61] (Copyright 2009 American Chemical Society); (b) Dependence of period for LSF (CR - coarse) and high spatial frequency (HSF) (FR-fine) ripples as a function of number $N$ for treatments on diamond with $\lambda=515 \mathrm{~nm}$ [63] (Copyright 2018 Elsevier).

At the resolution of the microscale, the reduced thermal effects drove the use of femtosecond laser pulses for the fabrication of accurate MEMSs and mesa structures for three-dimensional devices, that was demonstrated to be effective for diamond [64] and alternative to the standard ion beam techniques [65], as well as for the fabrication of microfluidic circuits [66].

All the experiments described in this review using ultrashort pulse lasers to induce LIPSSs on the surface of diamond films (divided into single crystal SCD, polycrystalline-PCD, nanocrystalline- $-\mathrm{NCD}$ ) are resumed in Table 1, where the main laser parameters (wavelength, pulse length, number of pulses $N$, fluence) are correlated with the values of the resulting HSF and LSF periodicities, alignment and depth. 
Table 1. Table resuming the ultrashort pulse laser parameters and the resulting features of the surface ripples, such as the periods $\Lambda_{\mathrm{HSF}}$ and $\Lambda_{\mathrm{LSF}}$, for high and low spatial frequency, alignment and depth, together with the diamond type from the references investigated in this paper. All the reported experimental results have common parameters in linear laser polarization and conditions of perpendicularity between the laser optical path and the diamond surface.

\begin{tabular}{|c|c|c|c|c|c|c|c|c|}
\hline $\begin{array}{c}\lambda \\
(\mathrm{nm})\end{array}$ & $\begin{array}{c}\text { Pulse } \\
\text { Length (fs) }\end{array}$ & $\begin{array}{c}N \text { of } \\
\text { Pulses }\end{array}$ & $\begin{array}{c}\text { Fluence } \\
\left(\mathrm{J} / \mathrm{cm}^{2}\right)\end{array}$ & $\begin{array}{c}\text { Diamond } \\
\text { Type }\end{array}$ & $\Lambda_{\mathrm{HSF}}(\mathrm{nm})$ & $\Lambda_{\mathrm{LSF}}(\mathrm{nm})$ & $\begin{array}{c}\text { Depth } \\
(\mathrm{nm})\end{array}$ & Reference \\
\hline 248 & 380 & 100 & 1.5 & PCD, SCD & $125\left(^{+}\right)$ & - & - & [56] \\
\hline 825 & 150 & 1000 & 2.5 & PCD, SCD & $\sim 400\left(^{+}\right)$ & - & - & [56] \\
\hline 800 & 150 & $10-1000$ & $1.5-4.7$ & SCD & - & $610 \pm 20\left(^{+}\right)$ & $90 \mathrm{~nm} / \mathrm{p}$ & [52] \\
\hline 400 & 100 & 3000 & 0.25 & PCD & $90(\|)$ & $380\left(^{+}\right)$ & - & [58] \\
\hline 800 & 100 & 3000 & 1.9 & PCD & $210\left(^{\|}\right)$ & $750\left(^{+}\right)$ & - & [58] \\
\hline 800 & 120 & 1000 & $0.16-0.83$ & SCD & $146 \pm 7\left(^{+}\right)$ & - & 500 & [59] \\
\hline 800 & 125 & $\begin{array}{l}3000 \\
8000\end{array}$ & $\begin{array}{l}1.9 \\
2.8\end{array}$ & SCD & $\begin{array}{l}170\left(^{+}\right) \\
190\left(^{+}\right)\end{array}$ & - & - & [60] \\
\hline 800 & 125 & $\begin{array}{l}10 \rightarrow \\
2000\end{array}$ & 1.9 & SCD & - & $600 \rightarrow 400\left(^{+}\right)$ & $10 \rightarrow 80$ & [61] \\
\hline 800 & 170 & $2-1000$ & $1.1-39.4$ & SCD & $140-240\left(^{+}\right)$ & $550-660\left(^{+}\right)$ & $10-50$ & [62] \\
\hline 800 & 120 & $250-500$ & 7.3 & PCD & $170\left(^{+}\right)$ & - & $400-500$ & {$[67,68]$} \\
\hline 400 & 120 & $250-500$ & 3.5 & PCD & $80\left(^{+}\right)$ & - & 200 & [69] \\
\hline 400 & 130 & $7-20$ & $2-6$ & SCD & & $\sim 400$ (॥) & 120 & [70] \\
\hline 800 & 60 & 5-100 & $0.5-1.3$ & $\begin{array}{l}\text { N-SCD } \\
\text { SCD }\end{array}$ & $\begin{array}{c}50\left(^{+}\right) \\
200(+)\end{array}$ & - & $>40$ & [71] \\
\hline 800 & 100 & $10-5000$ & $2-23$ & B-NCD & - & $420 \pm 16\left(^{+}\right)$ & 150 & [72] \\
\hline 515 & 230 & $25 \rightarrow 67$ & 6.36 & SCD & $110 \rightarrow 143(+)$ & - & $31-400 *$ & [73] \\
\hline 1030 & 230 & $50 \rightarrow 133$ & $7.56-9.95$ & SCD & $(190 \rightarrow 250) \pm 10(+)$ & - & $62-400 *$ & [73] \\
\hline 515 & 200 & $3 \rightarrow 100$ & $\sim 6.5$ & SCD & $\begin{array}{c}130 \rightarrow 100 \\
\pm 30\left(^{+}\right)\end{array}$ & $\begin{array}{c}450 \rightarrow 400 \\
\pm 40\left(^{+}\right)\end{array}$ & $\begin{array}{l}10-20 \\
\mathrm{~nm} / \mathrm{p}\end{array}$ & [63] \\
\hline
\end{tabular}

Notes: Diamond type: SCD, single crystal diamond; N-SCD, N-doped SCD; PCD, polycrystalline diamond; NCD, nanocrystalline diamond; B-NCD, Boron-doped NCD; In brackets, the symbol $\|$ corresponds to laser-induced periodic surface structures (LIPSS) alignment parallel to laser polarization, ${ }^{+}$symbol to an alignment perpendicular to laser polarization; * From simulations; References are in order of publication year.

\section{Black Diamond Films}

A specific case of nanostructuring applied to the overall diamond surface is represented by the development of black diamond films; namely, diamond films with drastically enhanced optical and electronic properties, developed by the authors' group. Diamond is a solar-blind material, consequently solar applications are apparently precluded to it. However, the use of intense laser pulses, especially with ultrashort duration, results in the surface texturing with a defined subwavelength HSF periodicity of the diamond surface, inducing a significant variation of the optical and electronic properties.

In the case of an ordered surface texturing structure, the period of the ripples is the most relevant parameter for the tailoring of the treated material's optical properties, since it mainly rules the optical reflectance similarly to a diffraction grating interacting with a radiation propagating in a free space. Following the indications reported in [74], where a uniform texturing was obtained on zinc oxide by a weighed raster of the laser spot on the surface of the material under treatment, with a particular attention to the estimation of the lateral and vertical overlap of pulses, the processing of the overall diamond surface was systematically performed on large areas [67] to probe the variation of the resulting optical properties, starting from conditions of semi-transparency typical of the untreated diamond plates. The laser treatments were performed under several controlled gas atmospheres as well as under high vacuum conditions, which are connected to the best nanostructuring results owing to reduced surface chemical reactions. A significant increase of absorptance was found in the visible 
and infrared range, with absorption peaks at multiples of the texturing periodicity. With $\lambda=800 \mathrm{~nm}$ and a high number of pulses $(250<N<500)$, the period $\Lambda_{\mathrm{HSF}}$ of linear structures was found to be about $170 \mathrm{~nm}$, coherently with the simulations and results also on other materials of [20,75], and predictable by Equation (1):

$$
\Lambda_{\mathrm{HSF}}=\lambda /(2 n(\lambda))
$$

where $n$ is the real part of the complex refractive index of diamond at $\lambda(n=2.40$ at $800 \mathrm{~nm}$ [76]). A recent work based on numerical simulations [77] estimates the HSF LIPSS periodicity in a precise range depending on plasma density with respect to the critical density of plasmon excitation [78], with a calculated periodicity range for diamond/air interaction at $\lambda=800 \mathrm{~nm}$ that substantially include that predicted by Equation (1). The same simulations confirm, by comparing predicted values with experimental results, also the dependence of $\Lambda_{\mathrm{HSF}}$ firstly on number of pulses, and secondly on laser fluence [73].

The optical absorptance of the surface-textured diamond plates was found to be an increasing function of the accumulated fluence (i.e., number of pulses impinging on the same surface unit) [79]. Values of solar absorptance, defined as the absorptance integrated over the solar spectrum, as high as $91.7 \%$ were obtained with samples originally having a solar absorptance of $45.4 \%$. The resulting material was named "black diamond" for the characteristic black color that qualitatively accounts for high values of optical absorption (Figure 7).

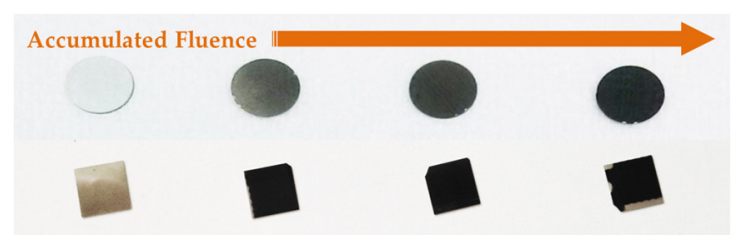

(a)

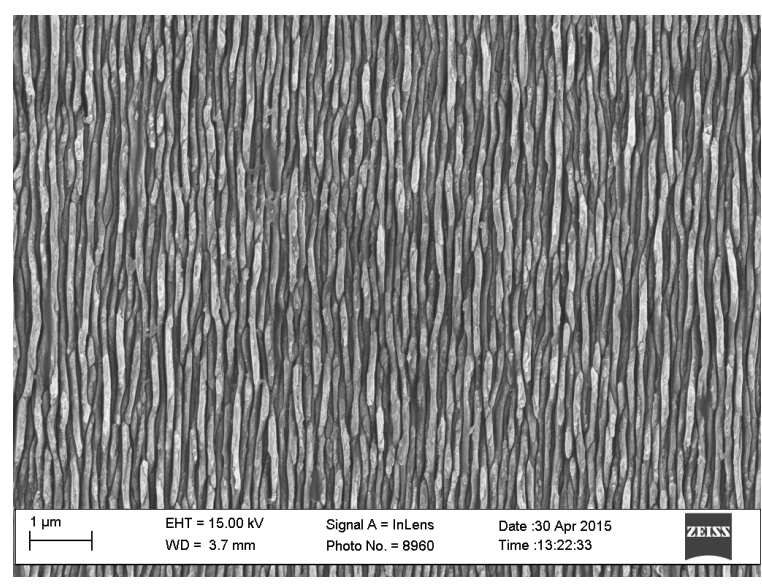

(b)

Figure 7. (a) Picture showing the increasing optical absorption capability of optical grade (upward) and thermal grade (downward and not in the same scale) diamond films as a function of increased laser accumulated fluence; (b) Microstructure of a typical black diamond film, treated at a laser wavelength of $800 \mathrm{~nm}$, attributing it the peculiar optical and electronic properties [68] (CC BY 4.0).

It is important to mention that the drastic increase in optical absorption capability is not absolutely due to the formation of graphitic regions on the diamond surface. Even though some graphitic regions are formed during the laser treatment [80] together with ablation debris, every non-diamond domain was removed by a selective oxidizing etching solution. Raman spectroscopy both in the visible $(514.5 \mathrm{~nm})$ and in the ultraviolet $(325 \mathrm{~nm}$, corresponding to a lower penetration depth and therefore inducing a Raman signal more sensitive to surface) did not show any additional $\mathrm{sp}^{2}$ features than those present in the pristine samples [81]. This was confirmed also by X-ray photoelectron spectroscopy, namely a very surface-sensitive technique.

Therefore, the enhanced optical properties are exclusively due to the ordered nanostructuring on the diamond surface that acts as a linear surface-relief subwavelength diffraction grating characterized by the period $\Lambda_{\mathrm{HSF}}$ and a height equal to the ripple depth $h$ that produces zero-order diffraction. In other words, the grating makes diffracted fields of order higher than zeroth evanescent, thus allowing 
the propagation of only the zeroth-order into the solid. Optically, it corresponds to the fabrication of a continuous layer on the diamond surface with a lower effective refractive index, with the effect of a better optical coupling and minimization of the reflection at the solid interface. Figure 8 shows the solar absorptance of the black diamond plates treated at different absorbed accumulated fluences. The larger absorptance values than the untreated films were confirmed also in the 2-25 $\mu \mathrm{m}$ IR wavelength range in [81], corresponding to a significant increase of the thermal emissivity coefficient from about 0.2 of pristine diamond to values $>0.6$. This is indicative that a careful development for the application of black diamond as a selective solar absorber operating at high temperatures is still to be performed by a better adjustment of the texturing parameters.

The engineering of the optical properties of black diamond is not the only interesting characteristic of surface texturing at the nanoscale. The extremely appealing feature that black diamond films presents is a significant improvement in the photoelectronic sensitivity for photons with sub-bandgap energy, as shown in Figure 9a [68]. It means that defect levels were introduced in the diamond electronic bandgap and that different electronic properties could be produced if they would be tuned in terms of density and energy position. The introduced defect states, acting similarly to intermediate bands [82], represent a staircase for the promotion of charge carriers to the related extended bands, and allow photogeneration and collection also for photons with an energy far lower than the diamond bandgap. In order to quantify the defect energy band, we defined the photoelectronic gain as the ratio between the quantum efficiency of the black diamond film and that of the pristine sample. Figure $9 \mathrm{~b}$ shows the photoelectronic gain, with which one can disentangle the effect of native defect levels from those introduced by the surface texturing, as a function of radiation wavelength. The gain appears as a broad band, composed by the contribution of the electronically active defects. Once we have learned to control its position and density, it will be possible to tune the electronic behavior of the resulting black diamond material.

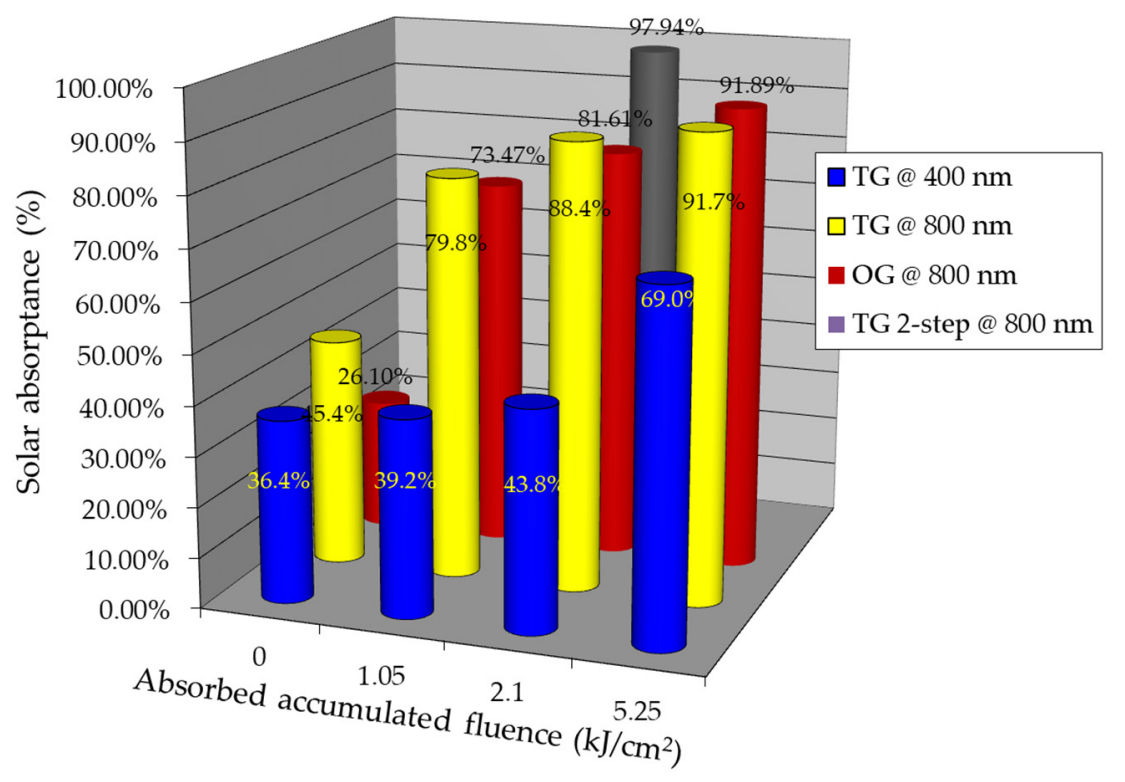

Figure 8. Solar absorptance values measured for different sets of black diamond films: Thermal grade (TG) samples treated at laser wavelengths of 400 and $800 \mathrm{~nm}$ with a single pass; optical grade (OG) samples treated at laser wavelength of $800 \mathrm{~nm}$ with a single pass; TG treated at laser wavelengths of $800 \mathrm{~nm}$ with a double pass. The values were derived from absorptance spectra measured by means of the Perkin Elmer Lambda 950 spectral photometer under total transmission and reflection measurements in a $150 \mathrm{~mm}$ integrating optical sphere in the wavelength range $200-2000 \mathrm{~nm}$. 


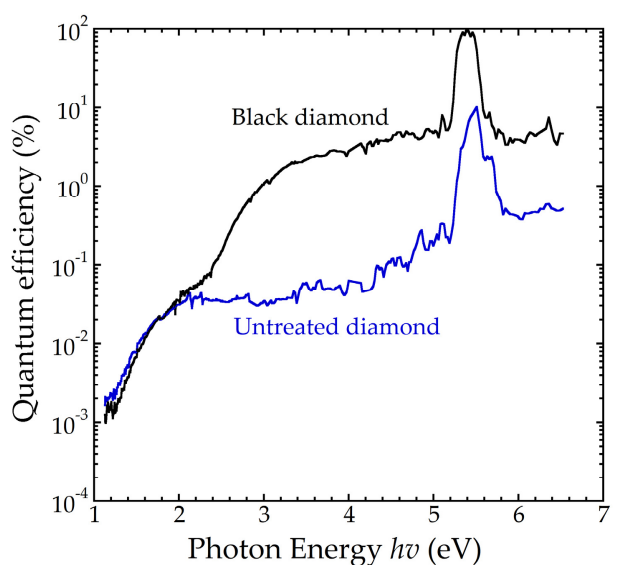

(a)

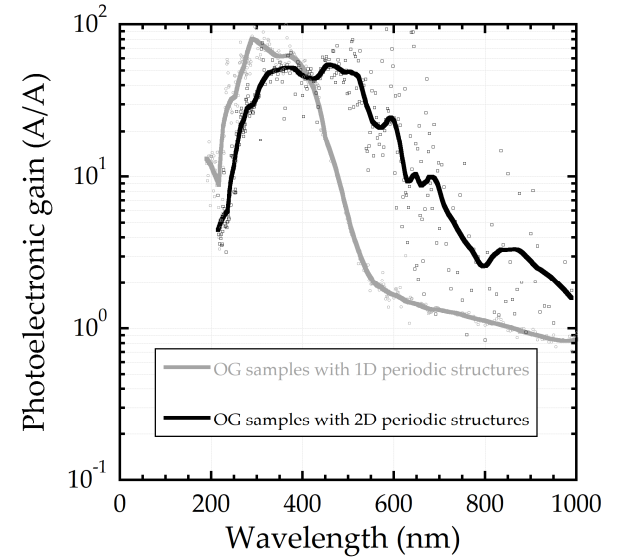

(b)

Figure 9. (a) Quantum efficiency as a function of radiation photon energy for a black diamond film and an untreated film [68] (CC BY 4.0). (b) Photoelectronic gain as a function of radiation wavelength for the optimally treated 1D-periodic optical-grade (OG, grey curve) and 2D-periodic thermal grade (TG, black curve) samples. The photoelectronic gain represents the ratio between the quantum efficiency of the black diamond film and that of the pristine sample [83] (CC BY NC ND).

The dimensionality of periodicity was found also to be important, as demonstrated by [83], where the passage from a 1D to a 2D periodicity, both obtained at $\lambda=800 \mathrm{~nm}$ and at the same accumulated fluence of $5.0 \mathrm{~kJ} / \mathrm{cm}^{2}$, allowed for the increase of solar absorptance up to $97.9 \%$ and more than an order of magnitude of quantum efficiency. The 2D periodic texturing was produced by a double step treatment consisting of a rotation of 90 degrees of the sample with respect to the first step, similarly to the attempt proposed in [59], where the rotation angle was 60 degrees. Even though not perfectly structured, the 2D periodic texturing indicated that a further confinement in another surface direction can be useful for capturing light and obtaining a more effective superposition of defect states within the bandgap. Furthermore, the energy position of the defect band was found to be wider and active even at longer wavelengths (up to $800 \mathrm{~nm}$ ), as shown in Figure 9b. Anyway, the activity of developing 2D periodic surface structures is ongoing according to a twofold strategy: (1) disproportioning the accumulated fluence by taking into account of the reduced ablation threshold of diamond after the first treatment; (2) using a circular (or elliptical) polarization for the production of nanocones on diamond surface, similarly to what performed with other materials [84].

By decreasing the laser wavelength from 800 to $400 \mathrm{~nm}$, Equation (1) was found to be confirmed. A periodicity of about $80 \mathrm{~nm}$ was obtained at $\lambda=400 \mathrm{~nm}$, where diamond refractive index is 2.46, under similar conditions of absorbed accumulated fluence with respect to $800 \mathrm{~nm}$ [69]. Consequently, the validity of Equation (1) suggests that a precise value of texturing periodicity can be controlled a priori by selecting the laser wavelength. This can be performed by equipping the laser system with commercial optical parametric amplifiers, which today can vary the output wavelength of a $800 \mathrm{~nm}$ pumping laser system from about 200 to $20 \mu \mathrm{m}$, but obviously with a reduced output optical fluence towards the range limits. Figure 10a shows the variation of the important surface texturing periodicity as a design parameter, ranging from about $50 \mathrm{~nm}$ to $4 \mu \mathrm{m}$ for a corresponding variation of the laser wavelength from $250 \mathrm{~nm}$ to $20 \mu \mathrm{m}$ (diamond refractive index was measured in [76]). It is interesting to mention that in nitrogen doped diamond films, treated at $\lambda=800 \mathrm{~nm}$, at high repetition rates and under ambient conditions, a carbonaceous structure with smaller periodic features of $50 \mathrm{~nm}$ emerged together with the characteristic diamond one [71]. Figure 10b shows a detail of $\Lambda_{\mathrm{HSF}}(\lambda)$ for a restricted wavelength range $200-1100 \mathrm{~nm}$ and comparison with the experimental values reported in Table 1. 


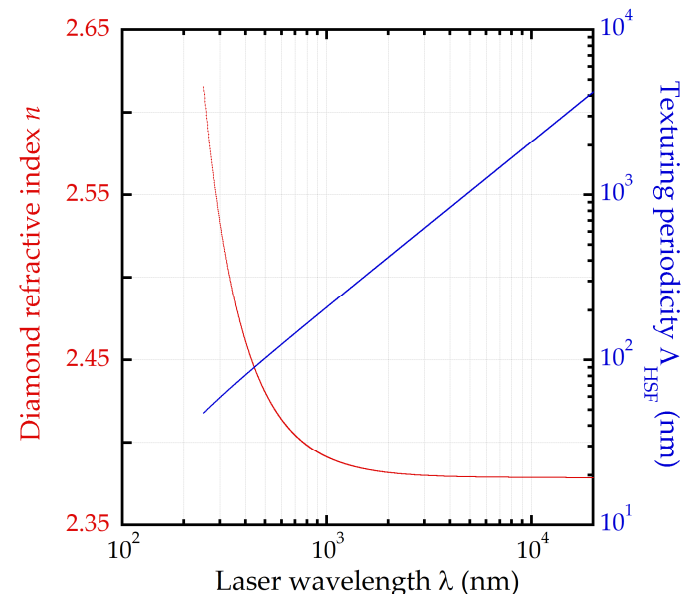

(a)

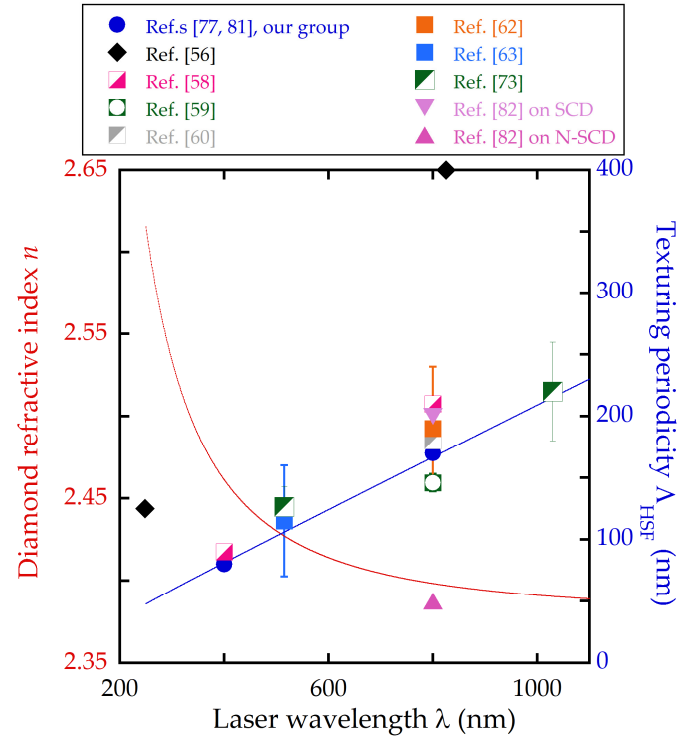

(b)

Figure 10. (a) Dependence of diamond refractive index [76] and related HSF texturing periodicity on the laser wavelength from about $200 \mathrm{~nm}$ to $20 \mu \mathrm{m}$, derived from the application of Equation (1); (b) Detail of the plot shown in (a) for a restricted wavelength range 200-1100 nm and comparison with the experimental values of $\Lambda_{\mathrm{HSF}}$ reported in Table 1 .

Another important parameter for the optical and electronic properties is the depth of the structures, namely the peak-to-valley height of the LIPSSs. At a wavelength of $800 \mathrm{~nm}$ and a high number of pulses ( $>250)$, the depth of the LIPSSs was estimated by scanning electron microscopy to range from 400 to $500 \mathrm{~nm}$. Similarly to a linear diffraction grating, the depth $\mathrm{h}$ of the nanostructures defines the longest radiation wavelength limit, approximately given by $h>\lambda_{\text {rad }} / 2$ [85]. It means that the wavelength limit ranges approximately from 800 to $1000 \mathrm{~nm}$ for structures obtained on diamond with a laser wavelength of $800 \mathrm{~nm}$ and the given fluence and pulse number. In case of smaller heights, the absorptance is reduced for long wavelengths. It is probably a case of black diamond films produced at $\lambda=400 \mathrm{~nm}$, where an accurate measurement of the LIPSSs' depth is ongoing; however, after a rough estimation, it should not be larger than $200 \mathrm{~nm}$. Also, for $\lambda=400 \mathrm{~nm}$, the solar absorptance increases with accumulated fluence. Conversely, even though an intermediate accumulated fluence is able to better tune the photoelectronic properties of the material, the quantum efficiency was not found to be improved with respect to the untreated film. Activity is here ongoing to understand if a constant accumulated fluence, resulting from the single pulse fluence times the number of pulses impinging on the same region, is an invariant parameter by changing reciprocally one parameter with respect to the other.

Black diamond films represent an example of defect engineering under development with the control of the nanostructure parameters (value and dimensionality of the periodicity, shape, depth, etc.) in order to tune the introduction of defect levels within the diamond bandgap. This is going to disclose a more complex way to tailor the optoelectronic properties of diamond that, similarly to traditional doping but with additional benefits coming from combined physical mechanisms, can be the key tool for more advanced applications for diamond than the present ones. This scientific strategy was proposed to the scientific community, as the defect engineering of diamond and can be extended also to the other wide bandgap semiconductors. 


\section{Applications of Surface Nanotextured Diamond Films}

Although the experiments of ultrashort pulse lasers and diamond surface started in 1999, the nanotextured diamond films have only recently begun to be a competitive candidate for practical applications. The texturing at the nanoscale opens the applicability for visible wavelength band optics, where the exceptional resilience of diamond is an added value. The most direct application of surface-treated thin diamond film at the nanoscales is as antireflection coatings and selective absorbers for thermal solar applications. A solar absorptance as high as about $98 \%$ represents a state-of-the-art value for solar receivers. However, the absorption selectivity has to be significantly enhanced, especially if the absorber has to operate at temperatures far higher than room temperature. The solution is a fine tuning of the nanostructure parameters such periodicity and depth, allowing for absorption of visible and near-IR and reflection of wavelengths longer than the mid-IR band (with a cutoff wavelength depending on the specific operating temperature).

Another specific and advanced application is the development of anti-reflection coatings for future diamond Raman lasers operating in the near-IR [70]. On the other hand, laser treatments of diamond/metals interfaces were proposed to enhance the electric properties of electrodes on diamond (e.g., in [86] with aluminum), with applications in electronics and development of sensors.

Another interesting characteristic of the laser-nanostructured surfaces is the super-hydrophobic behavior [87]. It could reserve an appealing application also for diamond, that, if hydrogen-terminated, has a noticeable hydrophobicity [88]. Anti-corrosion, anti-icing, and low flow-resistance properties of nanostructured surfaces open the route to aerospace applications, whereas anti-microbial characteristic enables biological applications that could be combined to the enhanced capability to absorb visible and infrared light. Conversely, if oxygen-terminated, the diamond surface is hydrophilic and the nanostructuring could increase the effective surface area of more than $50 \%$ with respect to the geometric area. These effects were recently exploited in Reference [72] to enhance the wettability properties of boron-doped diamond films used as electrochemical electrodes.

The specific application proposed by our group is for the development of high-temperature solar cells. The development of a photon-enhanced thermionic emission (PETE) converter allows for the achievement of high conversion efficiencies if used in concentrated solar systems [89]. Although III-V semiconductors can be bandgap-engineered at values compatible with solar spectrum photon energies, they need a coating able to reduce the electron affinity, usually based on alkali metal composites, in order to provide the necessary electron emission. The thermal stability of the emission coating, combined with the restricted structural stability in temperature of III-V compounds (roughly $<250{ }^{\circ} \mathrm{C}$ and $<450{ }^{\circ} \mathrm{C}$ for arsenides and phosphides, respectively), severely limits their full application for the PETE conversion. Conversely, hydrogen-terminated nitrogen-doped diamond has a great capability for emitting electrons owing to an effective work function of $1.7 \mathrm{eV}$. Such a property combined to surface texturing represents the main feature of the black diamond PETE cathode, structured according to a $\mathrm{p} / \mathrm{i} / \mathrm{n}$ device [90], where black diamond absorbs the solar radiation and enables the photogeneration of charge carriers. They are successively separated by the band bending formed at the interface between p-type and intrinsic regions [91], with electrons being injected by diffusion towards the intrinsic region. If electron mean free path is longer than the intrinsic region, they successfully reach the nitrogen-doped and hydrogen-terminated emitting surface, which is connected to a high probability of escaping towards the vacuum. Since the electron emission is sustained also by thermionic contribution due to the heating of the cathode, low conductivity microchannels are fabricated within the diamond bulk [43], connecting the two surfaces so to refill thermal electrons to the emitting surface. To conclude the device, a low work function anode and micrometer size dielectric spacers are necessary, but they are part of a complementary activity.

The strongest implication of the defect-engineering strategy at the basis of black diamond is related to the possibility of locally controlling the optoelectronic properties of diamond. With an accurate defect-engineering, regions able to capture the light could be possibly coupled to regions able to emit light produced by transitions between introduced defect levels and extended bands or 
by radiative recombination centers, such as in the case of $\mathrm{NV}^{-}$defects. The light can be transported by diamond microwave-guides surrounded by graphitic walls and distributed by embedded optical components (e.g., Fresnel lenses [92]); the same graphitic microstructures can also transport electrons. With the interchangeability between electric and optical signals, the most advanced application derived from laser structuring will probably be diamond-based 3D optoelectronic platforms.

Acknowledgments: The activity was supported by the European Community FP7 FET-Energy Project ProME ${ }^{3}$ $\mathrm{ThE}^{2} \mathrm{US}^{2}$ "Production Method of Electrical Energy by Enhanced Thermal Electron Emission by the Use of Superior Semiconductors", Grant Agreement No. 308975, website: www.prometheus-energy.eu.

Conflicts of Interest: The authors declare no conflict of interest.

\section{References}

1. Salvatori, S.; Girolami, M.; Oliva, P.; Conte, G.; Bolshakov, A.; Ralchenko, V.; Konov, V. Diamond device architectures for UV laser monitoring. Laser Phys. 2016, 26, 084005. [CrossRef]

2. Girolami, M.; Allegrini, P.; Conte, G.; Trucchi, D.M.; Ralchenko, V.G.; Salvatori, S. Diamond detectors for UV and X-ray source imaging. IEEE Electron Device Lett. 2012, 33, 224-226. [CrossRef]

3. Trucchi, D.M.; Allegrini, P.; Calvani, P.; Galbiati, A.; Oliver, K.; Conte, G. Very fast and priming-less single-crystal diamond X-ray dosimeters. IEEE Electron Device Lett. 2012, 33, 615-617. [CrossRef]

4. Girolami, M.; Bellucci, A.; Calvani, P.; Cazzaniga, C.; Rebai, M.; Rigamonti, D.; Tardocchi, M.; Pillon, M.; Trucchi, D.M. Mosaic diamond detectors for fast neutrons and large ionizing radiation fields. Phys. Status Solidi (a) 2015, 212, 2424-2430. [CrossRef]

5. Sussmann, R.S. CVD Diamond for Electronic Devices and Sensors; John Wiley \& Sons Ltd.: London, UK, 2009.

6. Balasubramaniam, Y.; Pobedinskas, P.; Janssens, S.D.; Sakr, G.; Jomard, F.; Turner, S.; Lu, Y.G.; Dexters, W.; Soltani, A.; Verbeeck, J.; et al. Thick homoepitaxial (110)-oriented phosphorus-doped n-type diamond. Appl. Phys. Lett. 2016, 109, 062105. [CrossRef]

7. Kato, H.; Takeuchi, D.; Ogura, M.; Yamada, T.; Kataoka, M.; Kimura, Y.; Sobue, S.; Nebel, C.E.; Yamasaki, S. Heavily phosphorus-doped nano-crystalline diamond electrode for thermionic emission application. Diam. Relat. Mater. 2016, 63, 165-168. [CrossRef]

8. Dutta, M.; Koeck, F.A.M.; Hathwar, R.; Goodnick, S.M.; Nemanich, R.J.; Chowdhury, S. Demonstration of diamond-based schottky p-i-n diode with blocking voltage >500 V. IEEE Electron Device Lett. 2016, 37, 1170-1173. [CrossRef]

9. Strobel, P.; Riedel, M.; Ristein, J.; Ley, L. Surface transfer doping of diamond. Nature 2004, 430, 439-441. [CrossRef] [PubMed]

10. Iacobucci, S.; Alippi, P.; Calvani, P.; Girolami, M.; Offi, F.; Petaccia, L.; Trucchi, D.M. Electronic structure of hydrogenated diamond: Microscopical insight into surface conductivity. Phys. Rev. B 2016, 94, 045307. [CrossRef]

11. Calvani, P.; Corsaro, A.; Girolami, M.; Sinisi, F.; Trucchi, D.M.; Rossi, M.C.; Conte, G.; Carta, S.; Giovine, E.; Lavanga, S. DC and RF performance of surface channel MESFETs on H-terminated polycrystalline diamond. Diam. Relat. Mater. 2009, 18, 786-788. [CrossRef]

12. Ueda, K.; Kasu, M.; Yamauchi, Y.; Makimoto, T.; Schwitters, M.; Twitchen, D.J.; Scarsbrook, G.A.; Coe, S.E. Diamond fet using high-quality polycrystalline diamond with $f_{t}$ of $45 \mathrm{GHz}$ and $f_{\max }$ of $120 \mathrm{GHz}$. IEEE Electron Device Lett. 2006, 27, 570-572. [CrossRef]

13. Hirama, K.; Sato, H.; Harada, Y.; Yamamoto, H.; Kasu, M. Diamond field-effect transistors with 1.3 A/mm drain current density by $\mathrm{Al}_{2} \mathrm{O}_{3}$ passivation layer. Jpn. J. Appl. Phys. 2012, 51, 090112.

14. Mildren, R.P. Intrinsic optical properties of diamond. In Optical Engineering of Diamond; Mildren, R.P., Rabeau, J.R., Eds.; Wiley-VCH Verlag GmbH \& Co. KGaA: Weinheim, Germany, 2013; pp. 1-34.

15. Konov, V.I.; Kononenko, T.V.; Kononenko, V.V. Laser micro- and nanoprocessing of diamond materials. In Intrinsic Optical Properties of Diamond; Mildren, R.P., Rabeau, J.R., Eds.; Wiley-VCH Verlag GmbH \& Co. KGaA: Weinheim, Germany, 2013; pp. 385-443.

16. Gattass, R.R.; Mazur, E. Inducing and probing non-thermal transitions in semiconductors using femtosecond laser pulses. Nat. Mater. 2002, 1, 217-224. 
17. He, F.; Liao, Y.; Lin, J.; Song, J.; Qiao, L.; Cheng, Y.; Sugioka, K. Femtosecond laser fabrication of monolithically integrated microfluidic sensors in glass. Sensors 2014, 14, 19402-19440. [CrossRef] [PubMed]

18. Sugioka, K.; Cheng, Y. Femtosecond laser three-dimensional micro- and nanofabrication. Appl. Phys. Rev. 2014, 1, 041303. [CrossRef]

19. Skolski, J.Z.P.; Römer, G.R.B.E.; Obona, J.V.; Ocelik, V.; Huis in't Veld, A.J.; De Hosson, J.T.M. Laser-induced periodic surface structures: Fingerprints of light localization. Phys. Rev. B 2012, 85, 075320. [CrossRef]

20. Buividas, R.; Rosa, L.; Sliupas, R.; Kudrius, T.; Slekys, G.; Datsyuk, V.; Juodkazis, S. Mechanism of fine ripple formation on surfaces of (semi)transparent materials via a half-wavelength cavity feedback. Nanotechnology 2011, 22, 055304. [CrossRef] [PubMed]

21. Du, D.; Liu, X.; Korn, G.; Squier, J.; Mourou, G. Laser-induced breakdown by impact ionization in $\mathrm{SiO}_{2}$ with pulse widths from $7 \mathrm{~ns}$ to $150 \mathrm{fs.} \mathrm{Appl.} \mathrm{Phys.} \mathrm{Lett.} \mathrm{1994,} \mathrm{64,} \mathrm{3071-3073.} \mathrm{[CrossRef]}$

22. Zamfirescu, M.; Ulmeanu, M.; Cretu, O.; Moldovan, A.; Epurescu, G.; Dinescu, M.; Dabu, R. Femtosecond laser induced periodic surface structures on ZnO thin films. J. Laser Micro/Nanoeng. 2009, 4, 7-10. [CrossRef]

23. Gattass, R.R.; Mazur, E. Femtosecond laser micromachining in transparent materials. Nat. Photonics 2008, 2, 219-225. [CrossRef]

24. Tull, B.R.; Carey, J.E.; Mazur, E.; McDonald, J.P.; Yalisove, S.M. Silicon surface morphologies after femtosecond laser irradiation. MRS Bull. 2006, 31, 626-633. [CrossRef]

25. Wu, C.; Crouch, C.H.; Zhao, L.; Carey, J.E.; Younkin, R.; Levinson, J.A.; Mazur, E.; Farrell, R.M.; Gothoskar, P.; Karger, A. Near-unity below-band-gap absorption by microstructured silicon. Appl. Phys. Lett. 2001, 78, 1850. [CrossRef]

26. Wang, J.; Guo, C. Formation of extraordinarily uniform periodic structures on metals induced by femtosecond laser pulses. J. Appl. Phys. 2006, 100, 023511. [CrossRef]

27. Vorobyev, A.Y.; Guo, C. Femtosecond laser blackening of platinum. J. Appl. Phys. 2008, 104, 053516. [CrossRef]

28. Vincenc Oboňa, J.; Ocelík, V.; Rao, J.C.; Skolski, J.Z.P.; Römer, G.R.B.E.; Huis in't Veld, A.J.; Hosson, J.T.M.D. Modification of Cu surface with picosecond laser pulses. Appl. Surf. Sci. 2014, 303, 118-124. [CrossRef]

29. Vorobyev, A.Y.; Guo, C. Femtosecond laser-induced periodic surface structure formation on tungsten. J. Appl. Phys. 2008, 104, 063523. [CrossRef]

30. Kotsedi, L.; Mthunzi, P.; Nuru, Z.Y.; Eaton, S.M.; Sechoghela, P.; Mongwaketsi, N.; Ramponi, R.; Maaza, M. Femtosecond laser surface structuring of molybdenum thin films. Appl. Surf. Sci. 2015, 353, 1334-1341. [CrossRef]

31. Vincenc Obona, J.; Ocelík, V.; Skolski, J.Z.P.; Mitko, V.S.; Römer, G.R.B.E.; Huis in't Veld, A.J.; De Hosson, J.T.M. On the surface topography of ultrashort laser pulse treated steel surfaces. Appl. Surf. Sci. 2011, 258, 1555-1560. [CrossRef]

32. Sciti, D.; Silvestroni, L.; Trucchi, D.M.; Cappelli, E.; Orlando, S.; Sani, E. Femtosecond laser treatments to tailor the optical properties of hafnium carbide for solar applications. Sol. Energy Mater. Sol. Cells 2015, 132, 460-466. [CrossRef]

33. Sciti, D.; Trucchi, D.M.; Bellucci, A.; Orlando, S.; Zoli, L.; Sani, E. Effect of surface texturing by femtosecond laser on tantalum carbide ceramics for solar receiver applications. Sol. Energy Mater. Sol. Cells 2017, 161, 1-6. [CrossRef]

34. Rehman, Z.U.; Janulewicz, K.A. Structural transformations in femtosecond laser-processed n-type $4 \mathrm{H}-\mathrm{SiC}$. Appl. Surf. Sci. 2016, 385, 1-8. [CrossRef]

35. Song, J.; Dai, Y.; Tao, W.; Gong, M.; Ma, G.; Zhao, Q.; Qiu, J. Surface birefringence of self-assembly periodic nanostructures induced on 6H-SiC surface by femtosecond laser. Appl. Surf. Sci. 2016, 363, 664-669. [CrossRef]

36. Wang, C.; Huo, H.; Johnson, M.; Shen, M.; Mazur, E. The thresholds of surface nano-/micro-morphology modifications with femtosecond laser pulse irradiations. Nanotechnology 2010, 21, 75304. [CrossRef] [PubMed]

37. Wang, C.Z.; Ho, K.M.; Shirk, M.D.; Molian, P.A. Laser-induced graphitization on a diamond (111) surface. Phys. Rev. Lett. 2000, 85, 4092-4095. [CrossRef] [PubMed]

38. Sun, B.; Salter, P.S.; Booth, M.J. High conductivity micro-wires in diamond following arbitrary paths. Appl. Phys. Lett. 2014, 105, 231105. [CrossRef] 
39. Oh, A.; Caylar, B.; Pomorski, M.; Wengler, T. A novel detector with graphitic electrodes in CVD diamond. Diam. Relat. Mater. 2013, 38, 9-13. [CrossRef]

40. Kononenko, T.; Ralchenko, V.; Bolshakov, A.; Konov, V.; Allegrini, P.; Pacilli, M.; Conte, G.; Spiriti, E. All-carbon detector with buried graphite pillars in CVD diamond. Appl. Phys. A 2014, 114, 297-300. [CrossRef]

41. Lagomarsino, S.; Bellini, M.; Corsi, C.; Gorelli, F.; Parrini, G.; Santoro, M.; Sciortino, S. Three-dimensional diamond detectors: Charge collection efficiency of graphitic electrodes. Appl. Phys. Lett. 2013, 103, 233507. [CrossRef]

42. Shimizu, M.; Shimotsuma, Y.; Sakakura, M.; Yuasa, T.; Homma, H.; Minowa, Y.; Tanaka, K.; Miura, K.; Hirao, K. Periodic metallo-dielectric structure in diamond. Opt. Express 2009, 17, 46-54. [CrossRef] [PubMed]

43. Girolami, M.; Criante, L.; Di Fonzo, F.; Lo Turco, S.; Mezzetti, A.; Notargiacomo, A.; Pea, M.; Bellucci, A.; Calvani, P.; Valentini, V.; et al. Graphite distributed electrodes for diamond-based photon-enhanced thermionic emission solar cells. Carbon 2017, 111, 48-53. [CrossRef]

44. Chen, Y.C.; Salter, P.S.; Knauer, S.; Weng, L.; Frangeskou, A.C.; Stephen, C.J.; Ishmael, S.N.; Dolan, P.R.; Johnson, S.; Green, B.L.; et al. Laser writing of coherent colour centres in diamond. Nat. Photonics 2017, 11, 77-81. [CrossRef]

45. Kononenko, V.V.; Vlasov, I.I.; Gololobov, V.M.; Kononenko, T.V.; Semenov, T.A.; Khomich, A.A.; Shershulin, V.A.; Krivobok, V.S.; Konov, V.I. Nitrogen-vacancy defects in diamond produced by femtosecond laser nanoablation technique. Appl. Phys. Lett. 2017, 111, 081101. [CrossRef]

46. Ralchenko, V.G.; Khomich, A.V.; Baranov, A.V.; Vlasov, I.I.; Konov, V.I. Fabrication of CVD diamond optics with antireflective surface structures. Phys. Status Solidi a 1999, 174, 171-176. [CrossRef]

47. Kononenko, T.V.; Kononenko, V.V.; Konov, V.I.; Pimenov, S.M.; Garnov, S.V.; Tishchenko, A.V.; Prokhorov, A.M.; Khomich, A.V. Formation of antireflective surface structures on diamond films by laser patterning. Appl. Phys. A 1999, 68, 99-102. [CrossRef]

48. Gloor, S.; Romano, V.; Luthy, W.; Weber, H.P.; Kononenko, V.V.; Pimenov, S.M.; Konov, V.I.; Khomich, A.V. Antireflection structures written by excimer laser on CVD diamond. Appl. Phys. A 2000, 70, 547-550. [CrossRef]

49. Tosin, P.; Blatter, A.; Lüthy, W. Laser-induced surface structures on diamond films. J. Appl. Phys. 1995, 78, 3797-3800. [CrossRef]

50. Verevkin, Y.K.; Bronnikova, N.G.; Korolikhin, V.V.; Gushchina, Y.Y.; Petryakov, V.N.; Filatov, D.O.; Bityurin, N.M.; Kruglov, A.V.; Levichev, V.V. Formation of two-dimensional periodic nanostructures on fused quartz, polyimide, and polycrystalline diamond by pulsed four-wave interference laser modification. Tech. Phys. 2003, 48, 757-760. [CrossRef]

51. Komlenok, M.S.; Kononenko, V.V.; Ralchenko, V.G.; Pimenov, S.M.; Konov, V.I. Laser induced nanoablation of diamond materials. Phys. Procedia 2011, 12, 37-45. [CrossRef]

52. Dumitru, G.; Romano, V.; Weber, H.P.; Sentis, M.; Marine, W. Femtosecond ablation of ultrahard materials. Appl. Phys. A Mater. Sci. Process. 2002, 74, 729-739. [CrossRef]

53. Mildren, R.P.; Downes, J.E.; Brown, J.D.; Johnston, B.F.; Granados, E.; Spence, D.J.; Lehmann, A.; Weston, L.; Bramble, A. Characteristics of 2-photon ultraviolet laser etching of diamond. Opt. Mater. Express 2011, 1, 576-585. [CrossRef]

54. Lehmann, A.; Bradac, C.; Mildren, R.P. Two-photon polarization-selective etching of emergent nano-structures on diamond surfaces. Nat. Commun. 2014, 5, 3341. [CrossRef] [PubMed]

55. Takayama, N.; Yan, J. Mechanisms of micro-groove formation on single-crystal diamond by a nanosecond pulsed laser. J. Mater. Process. Technol. 2017, 243, 299-311. [CrossRef]

56. Ozkan, A.M.; Malshe, A.P.; Railkar, T.A.; Brown, W.D.; Shirk, M.D.; Molian, P.A. Femtosecond laser-induced periodic structure writing on diamond crystals and microclusters. Appl. Phys. Lett. 1999, 75, 3716. [CrossRef]

57. Ageev, V.P.; Bullov, L.; Konov, V.I.; Kuzmichev, A.V.; Pimenov, S.M.; Prokhorov, A.M.; Ralchenko, V.G.; Spitsyn, B.V.; Capliev, B.I. Interaction of laser light with diamond films. Sov. Phys. Dokl. 1988, 33, 840-842.

58. Wu, Q.; Ma, Y.; Fang, R.; Liao, Y.; Yu, Q.; Chen, X.; Wang, K. Femtosecond laser-induced periodic surface structure on diamond film. Appl. Phys. Lett. 2003, 82, 1703. [CrossRef]

59. Shinoda, M.; Gattass, R.R.; Mazur, E. Femtosecond laser-induced formation of nanometer-width grooves on synthetic single-crystal diamond surfaces. J. Appl. Phys. 2009, 105, 053102. [CrossRef] 
60. Huang, M.; Zhao, F.; Cheng, Y.; Xu, N.; Xu, Z. Mechanisms of ultrafast laser-induced deep-subwavelength gratings on graphite and diamond. Phys. Rev. B 2009, 79, 125436. [CrossRef]

61. Huang, M.; Zhao, F.; Cheng, Y.; Xu, N.; Xu, Z. Origin of laser-induced near-subwavelength ripples: Interference between surface plasmons and incident laser. ACS Nano 2009, 3, 4062-4070. [CrossRef] [PubMed]

62. Hsu, E.M.; Mailman, N.A.; Botton, G.A.; Haugen, H.K. Microscopic investigation of single-crystal diamond following ultrafast laser irradiation. Appl. Phys. A 2010, 103, 185-192. [CrossRef]

63. Apostolova, T.; Obreshkov, B.D.; Ionin, A.A.; Kudryashov, S.I.; Makarov, S.V.; Mel'nik, N.N.; Rudenko, A.A. Ultrafast photoionization and excitation of surface-plasmon-polaritons on diamond surfaces. Appl. Surf. Sci. 2018, 427, 334-343. [CrossRef]

64. Zalloum, O.H.Y.; Parrish, M.; Terekhov, A.; Hofmeister, W. On femtosecond micromachining of HPHT single-crystal diamond with direct laser writing using tight focusing. Opt. Express 2010, 18, 13122-13335. [CrossRef] [PubMed]

65. Sumant, A.V.; Auciello, O.; Liao, M.; Williams, O.A. Mems/nems based on mono-, nano-, and ultrananocrystalline diamond films. MRS Bull. 2014, 39, 511-516. [CrossRef]

66. Su, S.; Li, J.; Lee, G.C.B.; Sugden, K.; Webb, D.; Ye, H. Femtosecond laser-induced microstructures on diamond for microfluidic sensing device applications. Appl. Phys. Lett. 2013, 102, 231913. [CrossRef]

67. Calvani, P.; Bellucci, A.; Girolami, M.; Orlando, S.; Valentini, V.; Lettino, A.; Trucchi, D.M. Optical properties of femtosecond laser-treated diamond. Appl. Phys. A Mater. Sci. Process. 2014, 117, 25-29. [CrossRef]

68. Calvani, P.; Bellucci, A.; Girolami, M.; Orlando, S.; Valentini, V.; Polini, R.; Trucchi, D.M. Black diamond for solar energy conversion. Carbon 2016, 105, 401-407. [CrossRef]

69. Girolami, M.; Bellucci, A.; Mastellone, M.; Orlando, S.; Valentini, V.; Montereali, R.M.; Vincenti, M.A.; Polini, R.; Trucchi, D.M. Impact of laser wavelength on the optical and electronic properties of black diamond. Phys. Status Solidi (a) 2017. [CrossRef]

70. Granados, E.; Martinez-Calderon, M.; Gomez, M.; Rodriguez, A.; Olaizola, S.M. Photonic structures in diamond based on femtosecond uv laser induced periodic surface structuring (LIPSS). Opt. Express 2017, 25, 15330. [CrossRef] [PubMed]

71. Forster, M.; Huber, C.; Armbruster, O.; Kalish, R.; Kautek, W. 50-nanometer femtosecond pulse laser induced periodic surface structures on nitrogen-doped diamond. Diam. Relat. Mater. 2017, 74, 114-118. [CrossRef]

72. Granados, E.; Calderon, M.M.; Krzywinski, J.; Wörner, E.; Rodriguez, A.; Aranzadi, M.G.; Olaizola, S.M. Enhancement of surface area and wettability properties of boron doped diamond by femtosecond laser-induced periodic surface structuring. Opt. Mater. Express 2017, 7, 3389. [CrossRef]

73. Miyaji, G.; Miyazaki, K. Origin of periodicity in nanostructuring on thin film surfaces ablated with femtosecond laser pulses. Opt. Express 2008, 16, 16265-16271. [CrossRef] [PubMed]

74. Huang, M.; Zhao, F.; Cheng, Y.; Xu, N.; Xu, Z. Large area uniform nanostructures fabricated by direct femtosecond laser ablation. Opt. Express 2008, 16, 19354-19365. [CrossRef] [PubMed]

75. Borowiec, A.; Haugen, H.K. Subwavelength ripple formation on the surfaces of compound semiconductors irradiated with femtosecond laser pulses. Appl. Phys. Lett. 2003, 82, 4462-4464. [CrossRef]

76. Turri, G.; Webster, S.; Chen, Y.; Wickham, B.; Bennett, A.; Bass, M. Index of refraction from the near-ultraviolet to the near-infrared from a single crystal microwave-assisted CVD diamond. Opt. Mater. Express 2017, 7, 855-859. [CrossRef]

77. Faryad, M.; Abdelmalek, A.; Bedrane, Z.; Amara, E.-H.; Eaton, S.M.; Ramponi, R. How plasmonic excitation influences the LIPSS formation on diamond during multipulse femtosecond laser irradiation? EPJ Web Conf. 2017, 139, 00008.

78. Abdelmalek, A.; Sotillo, B.; Bedrane, Z.; Bharadwaj, V.; Pietralunga, S.; Ramponi, R.; Amara, E.-H.; Eaton, S.M. Origin of femtosecond laser induced periodic nanostructure on diamond. AIP Adv. 2017, 7, 105105. [CrossRef]

79. Calvani, P.; Bellucci, A.; Girolami, M.; Orlando, S.; Valentini, V.; Polini, R.; Trucchi, D.M. Absorptance enhancement in fs-laser-treated cvd diamond. Phys. Status Solidi (a) 2015, 212, 2463-2467. [CrossRef]

80. Rehman, Z.U.; Janulewicz, K.A. Structural transformation of monocrystalline diamond driven by ultrashort laser pulses. Diam. Relat. Mater. 2016, 70, 194-200. [CrossRef]

81. Calvani, P.; Bellucci, A.; Girolami, M.; Orlando, S.; Valentini, V.; Polini, R.; Mezzetti, A.; Di Fonzo, F.; Trucchi, D.M. Infrared absorption of fs-laser textured cvd diamond. Appl. Phys. A 2016, 122, 211. [CrossRef] 
82. Luque, A.; Martì, A.; Stanley, C. Understanding intermediate-band solar cells. Nat. Photonics 2012, 6, 146-152. [CrossRef]

83. Bellucci, A.; Calvani, P.; Girolami, M.; Orlando, S.; Polini, R.; Trucchi, D.M. Optimization of black diamond films for solar energy conversion. Appl. Surf. Sci. 2016, 380, 8-11. [CrossRef]

84. Varlamova, O.; Costache, F.; Reif, J.; Bestehorn, M. Self-organized pattern formation upon femtosecond laser ablation by circularly polarized light. Appl. Surf. Sci. 2006, 252, 4702-4706. [CrossRef]

85. Gombert, A.; Glaubitt, W.; Rose, K.; Dreibholz, J.; Zanke, C.; Blasi, B.; Heinzel, A.; Horbelt, W.; Sporn, D.; Doll, W.; et al. Glazing with very high solar transmittance. Sol. Energy 1998, 62, 177-188. [CrossRef]

86. Okada, T.; Tomita, T.; Ueki, T.; Masai, Y.; Bando, Y.; Tanaka, Y. Femtosecond laser-induced modification at aluminum/diamond interface. Jpn. J. Appl. Phys. 2017, 56, 026601. [CrossRef]

87. Vorobyev, A.Y.; Guo, C. Multifunctional surfaces produced by femtosecond laser pulses. J. Appl. Phys. 2015, 117, 033103. [CrossRef]

88. Ostrovskaya, L.; Perevertailo, V.; Ralchenko, V.; Saveliev, A.; Zhuravlev, V. Wettability of nanocrystalline diamond films. Diam. Relat. Mater. 2007, 16, 2109-2113. [CrossRef]

89. Schwede, J.W.; Bargatin, I.; Riley, D.C.; Hardin, B.E.; Rosenthal, S.J.; Sun, Y.; Schmitt, F.; Pianetta, P.; Howe, R.T.; Shen, Z.; et al. Photon-enhanced thermionic emission for solar concentrator systems. Nat. Mater. 2010, 9, 762-767. [CrossRef] [PubMed]

90. Bellucci, A.; Calvani, P.; Girolami, M.; Trucchi, D.M. Defect Engineering of Diamond Cathodes for High Temperature Solar Cells. In Proceedings of the 2015 IEEE 15th International Conference on Environment and Electrical Engineering, Rome, Italy, 10-13 June 2015; pp. 1616-1619.

91. Bellucci, A.; Girolami, M.; Calvani, P.; Michaelson, S.; Hoffman, A.; Carcelen, V.; Trucchi, D.M. Buried boron doped layer for CVD diamond photo-thermionic cathodes. IEEE Trans. Nanotechnol. 2016, 15, 862-866. [CrossRef]

92. Kumar, K.; Lee, K.K.C.; Li, J.; Nogami, J.; Kherani, N.P.; Herman, P.R. Quantized structuring of transparent films with femtosecond laser interference. Light Sci. Appl. 2014, 3, e157. [CrossRef]

(C) 2017 by the authors. Licensee MDPI, Basel, Switzerland. This article is an open access article distributed under the terms and conditions of the Creative Commons Attribution (CC BY) license (http:/ / creativecommons.org/licenses/by/4.0/). 